\title{
SECOND TRIMESTER UTERINE RUPTURE
}

Mandavi Rai ${ }^{1}$, Vidya Kamble ${ }^{2}$, Chatterjee ${ }^{3}$, B. G. Boricha ${ }^{4}$

\section{HOW TO CITE THIS ARTICLE:}

Mandavi Rai, Vidya Kamble. Chatterjee, B. G. Boricha. "Second Trimester Uterine Rupture". Journal of Evolution of Medical and Dental Sciences 2014; Vol. 3, Issue 14, April 07; Page: 3764-3769,

DOI: $10.14260 /$ jemds/2014/2357

ABSTRACT: OBJECTIVE: Presenting a case of uterine rupture as early as 20 weeks of gestation after classical caesarian section done with short inter pregnancy duration and inter delivery duration of 9 months. CASE: 26 years old women gravida 2, para 1, and Death 1 with 20 weeks gestation with history of classical c-section done 9 months back in rural area (Bihar) for IUFD (cause not known) presented to out-patient department with abdominal pain, uterine contraction \& severe scar tenderness present. Patient was sent for USG and she followed up in OPD within an hour with the USG report showing single live intrauterine pregnancy of 19 weeks and 5 days and told that her pain had subsided. Suspecting a uterine rupture a repeat USG was done which showed a totally different picture suggesting $3.2 \mathrm{~cm}$ rupture in the anterior wall with protrusion of fetal parts, limb in the anterior pouch, with amniotic fluid surrounding it. FHS was present/ irregular. No liquor in uterine cavity, No Hemoperitoneum. Cervical length $2 \mathrm{~cm}$. On Examination Uterus was relaxed. On Exploratory Laparotomy, Classical scar rupture was found and, fetus and placenta removed. Scar was sutured back and uterus preserved. CONCLUSION: Spontaneous uterine rupture after classical caesarian section and short inter delivery duration can occur as early as 19-20 weeks of gestation. Uterine rupture should be considered as one of the causes of severe abdominal pain in early second trimester.

\section{INTRODUCTION:}

1. Spontaneous rupture of ante-partum uterus is uncommon in $1^{\text {st }}$ and $2^{\text {nd }}$ trimester. ${ }^{1}$

2. Uterine rupture mostly occurs due to previous $\mathrm{C}$-section. ${ }^{2,3,4}$

3. Risk of rupture in classical (vertical) section is greater than transverse one in subsequent pregnancy. 3,4

4. Risk factors for uterine rupture include myomectomy, septoplasty, metroplasty, trauma, congenital uterine anomalies (esp. ectopic in rudimentary horn), inadequate treatment of endometriosis, placental abruption.2,3,4

5. There are many that play an important role in increasing incidence of uterine rupture or dehiscence of previous C-section eg.,5,6

1. Type of section done(The classical scar at the upper part (body) of uterus is more vulnerable to ruptures and can cause more serious complication to mother and baby)

2. Multiparty.

3. Post-op complication that may occur as in failures, which is an imp factor for progress of next pregnancy and delivery

4. Co morbidities of patient

5. Skill and experience of surgeon. 
- The risk of uterine rupture in the presence of defective scar is related to the degree of thinning of the lower uterine segment and scar thickness as measured by ultrasound. In other words if niche is deeper or the overlying myometrium is thinner the risk of above mentioned complications in subsequent pregnancy is higher. 7,8

\section{CASE REPORT:}

- 26 years old female G2 P1 D1 followed in the OPD with localized supra-pubic pain and tenderness over whole abdomen.

- 9 months back she had a classical caesarean section owing to IUFD (cause of IUFD not known) in rural area of Bihar.

- She had no bleeding per vagina, Haematuria, chest or shoulder pain and had no medical or surgical illness in past.

- Patients pulse was 82/Min., Blood pressure - 110/80 mm hg, Respiratory Rate - 16/min., and temperature $-37^{\circ} \mathrm{C}$.

- On examination generalized tenderness and scar tenderness was present, vertical scar of previous classical section present. Contraction was present.

- On P/V examination cervical OS was patulous, anterior, soft

- Patient was send for USG and she followed up in OPD within an hour with USG report showing single live intrauterine pregnancy of 19 weeks \& 5 days and told that her pain had subsided.

- Suspecting a uterine rupture a repeat USG was done which showed a totally different picture suggesting $3.2 \mathrm{~cm}$ rupture in anterior wall with protrusion of fetal parts, limb in the anterior pouch, with amniotic fluid surrounding it.

- FHS was present/irregular, cervical length $2 \mathrm{~cm}$.

- No liquor in uterine cavity and on examination uterus was relaxed.

- Patient was immediately transferred to OT with arrangement of blood.

- Under General anaesthesia laparotomy was done.

- Pfannenstiel incision taken and after separation of rectus muscle protrusion of amniotic sac with limb of baby was seen through which fetal parts were protruding and through which dead fetus with placenta were removed.

- Repair of the rupture was performed haemostasis achieved and abdomen closed in layers

- Blood loss was around 300-400 $\mathrm{ml}$ and urine was clear throughout the operation.

- Operating time was around $80 \mathrm{~min}$. and patient recovered in 15-20 minute. No blood transfusion.

- Post-op patient was covered with broad spectrum antibiotics.

- Second day post-op urinary catheter was removed and for the seven days she progressed well and was discharged on $8^{\text {th }}$ day.

- $\quad$ On discharge her pulse was $80 / \mathrm{min}$., temperature $36.8^{\circ} \mathrm{C}, \mathrm{BP}-110 / 80 \mathrm{~mm}$ hg and $\mathrm{Hb}$ was 11.3 gm $\%$.

\section{DISCUSSION:}

Uterine ruptures could be divided into complete and incomplete (dehiscence) ruptures.

Incomplete uterine rupture or dehiscence, the myometrium is disrupted but the serosa is intact. Full complete tear of uterine wall results in complete uterine ruptures. ${ }^{9}, 10$ 
Compared to complete uterine rupture, uterine dehiscence has much lower maternal and neonatal morbidity. Perinatal deaths occurred as a result of uterine rupture, Compared to no perinatal deaths due to uterine rupture among women undergoing elective repeat caesarean delivery. The risk of uterine rupture has risen recently especially in developed countries due to increased rate of caesarean deliveries. ${ }^{11,2,7,8}$

The frequency of uterine rupture ranges between 0.2 to $3.8 \%$

\section{Incidence of scar rupture:}

1x previous LSCS (spontaneous labor): 0.5\%

1x previous LSCS (TOL without prostaglandins): 0.8\%

$1 \mathrm{x}$ previous LSCS (TOL with prostaglandins): $2.5 \%$

1x previous classical CS 4-9\%

2x previous LSCS 8-9\%

A complete uterine rupture cannot usually be predicted and it suddenly occurs during labour of or delivery. Several concomitant symptoms of eminent uterine rupture include: Abdominal pain or tenderness and onset of sharp pain at the site of previous scar or supra pubic pain, Deceleration of FHS. ,Sharp pain between contractions, Vaginal bleeding Recursion of the fetal head (baby's head moving back up in the birth canal), A popping sensation, Palpation of fetal parts outside the uterus upon Leopold manoeuvres, High presenting part upon vaginal examination.7,8,11

\begin{tabular}{|l|l|}
\hline Increased Rate of Uterine Rupture & Decreased Rate of Uterine Rupture \\
\hline Classic hysterotomy & Spontaneous labor \\
\hline Two or more caesarean deliveries & Prior vaginal delivery \\
\hline Single-layer closure & Longer interpregnancy interval \\
\hline Induction of labor & Preterm delivery \\
\hline Use of prostaglandins & \\
\hline Short interpregnancy interval & \\
\hline $\begin{array}{l}\text { Infection at prior caesarean } \\
\text { delivery }\end{array}$ & \\
\hline
\end{tabular}

Emergency exploratory laparotomy and delivery are proposed for the treatment of ruptured uterus.11, 12

\section{COMMENT:}

- Spontaneous uterine rupture after classical C-section and short inter-delivery duration can occur as early as 19-20 weeks of gestation.

- Uterine rupture is to be considered one of the causes of severe abdominal pain in $2^{\text {nd }}$ trimester. It is recommended to look for continuous myometrial band and measure its thickness especially if patient complains of pain or contractions. 
- She had previous classical C-section and she is not educated, which in my opinion played a very important role in this patient as well as other patient.

- If the patient had been educated she may have sought for early antenatal care and management.

- Importance of contraception should also be explained to patient especially those who have undergone classical C-section and interdelivery duration should be at least 3-4 years.

- And postpartum nutritional support should be given to the patient.

\section{REFERENCES:}

1. Abdulghani, N. (1993) Risk factors for Maternal Mortality among women using Hospitals in North Yemen. A thesis presented for the degree of PhD. D. in the Faculty of Medicine University of London.

2. Nouria M, Salama A et al. Pregnancy in the malformed uterus. Study of 366 pregnancies. Tunis Med 1998. 76, 376-379

3. Leung A.S, Leung E.K, Paul R.H. Uterine rupture after previous caesarean delivery, maternal and fetal consequences. Am J Obstet Gynecol 1993. 169, 945-950

4. Walsh CA, O'Sullivan RJ, Foley ME. Unexplained prelabor uterine rupture in a term primigravida. Obstetrics and Gynecology 2006;108 (3 Pt 2): 725-7.

5. Chamberlain, G. (1999) Obstetric by ten Teachers sixteenth edition. Great Britain 308

6. Caesarean section, NICE Clinical Guideline (2004).

7. Grobman WA, Lai Y, Landon MB et al. Prediction of uterine rupture associated with attempted vaginal birth after cesarean delivery. Am J Obstet Gynecol. 2008 Jul;199(1):30.e1-5. doi: 10.1016/j.ajog.2008.03.039. Epub 2008 Apr 25.

8. Zwart JJ, Richters JM, Ory F et al. Severe maternal morbidity during pregnancy, delivery and puerperium in the Netherlands: a nationwide population-based study of 371, 000 pregnancies. BJOG. 2008 Jun; 115 (7):842-50.

9. Chibber R, El-Saleh E, Fadhli RA, Jassar WA, Harmi JA. Uterine rupture and subsequent pregnancy outcome - how safe is it? A 25-year study. J Matern Fetal Neonatal Med 23 (5): 4214. doi:10.3 (March 2010). 109/14767050903440489. PMID 20230321

10. Uterine Rupture in Pregnancy: eMedicine Obstetrics and Gynecology. Retrieved 2010-03-23.

11. Guise JM, Eden K, Emeis C, et al; Vaginal birth after cesarean: new insights. Evid Rep Technol Assess (Full Rep). 2010 Mar; (191):1-397.

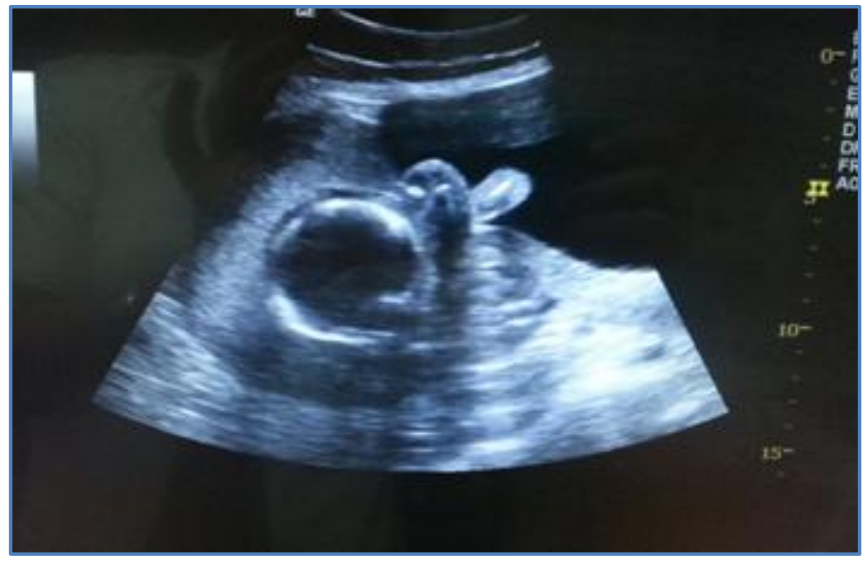




\section{CASE REPORT}

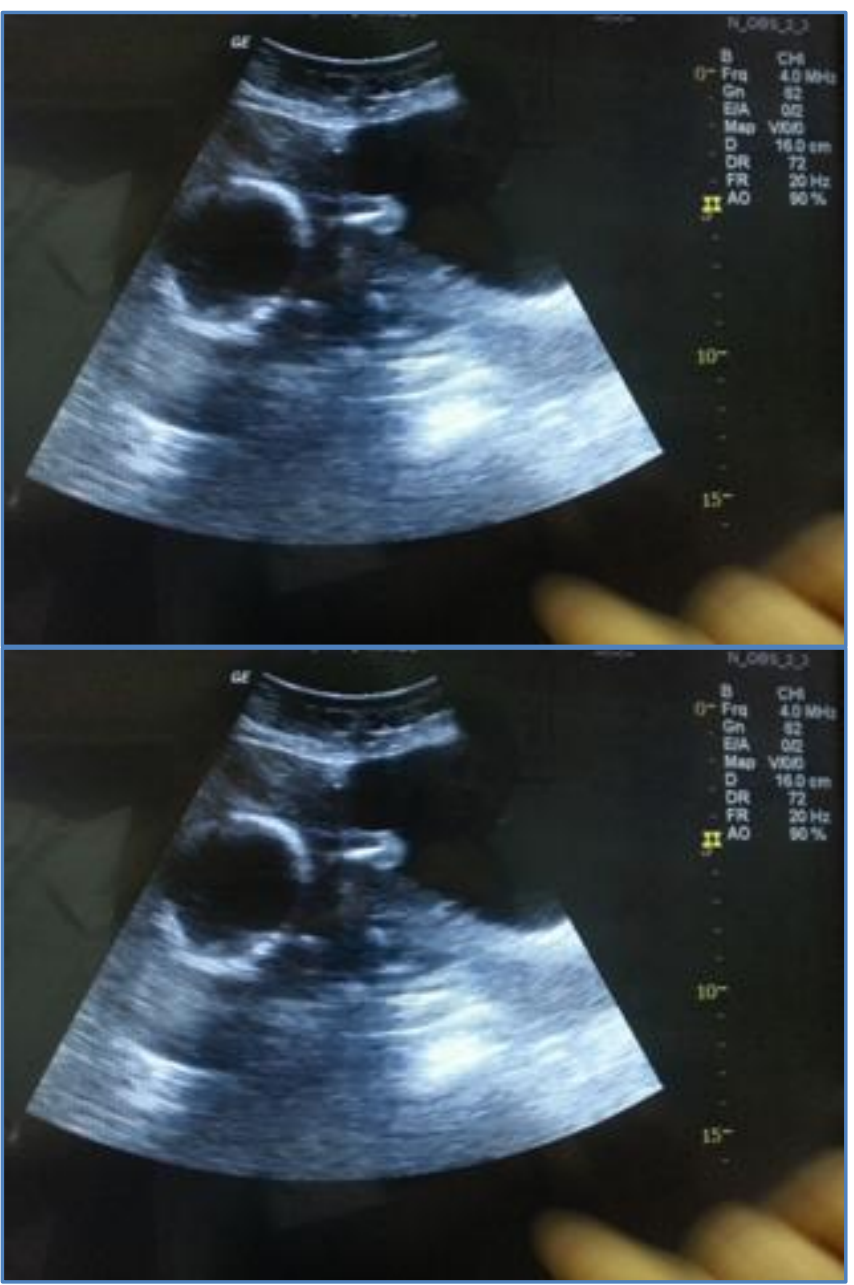

\section{RADIOLOGICAL FINDINGS OF UT: ERINE RUPTURE}
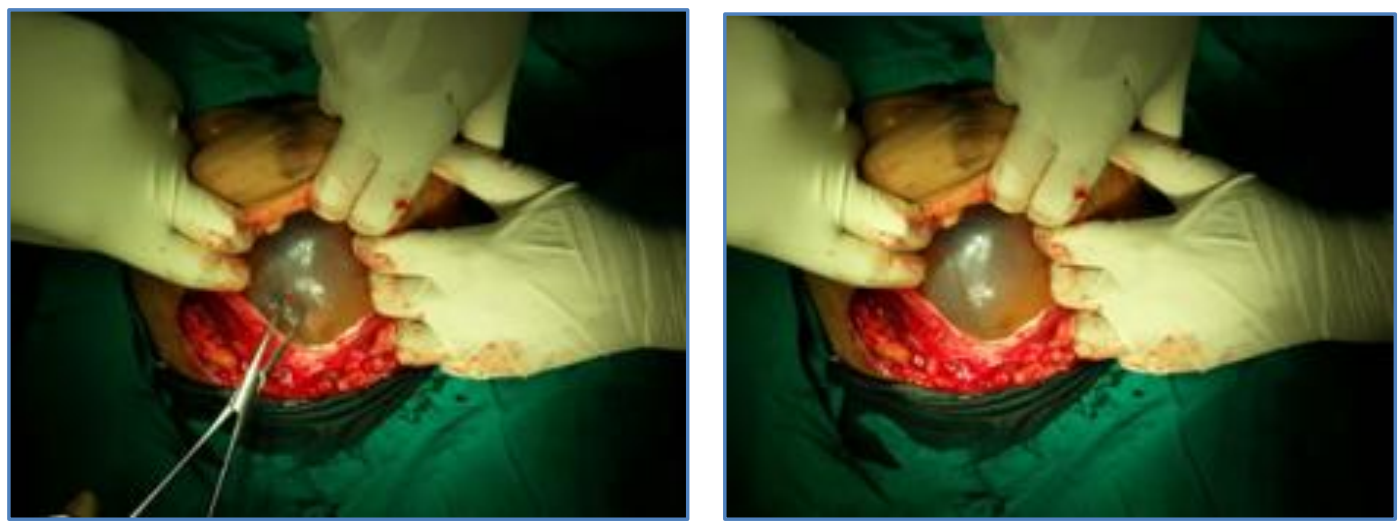


\section{CASE REPORT}
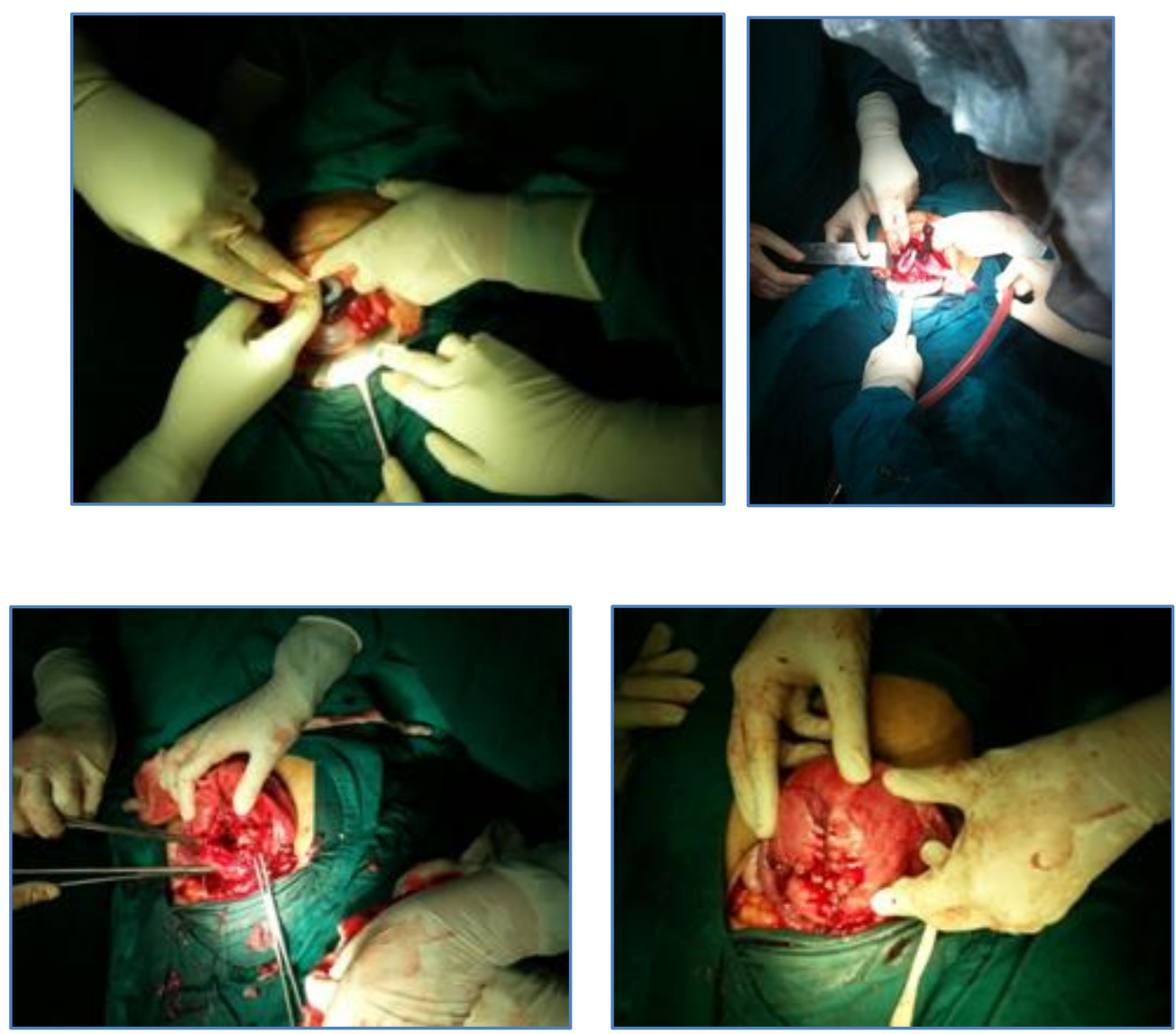

INTRAOPERATIVE FINDINGS

\section{AUTHORS:}

1. Mandavi Rai

2. Vidya Kamble

3. Chatterjee

4. B. G. Boricha

\section{PARTICULARS OF CONTRIBUTORS:}

1. $2^{\text {nd }}$ Year Post Graduate Student, Department of Obstetrics and Gynaecology, Mahatma Gandhi Mission Medical College and Hospital, Kalamboli, Navi, Mumbai.

2. Lecturer, Department of Obstetrics and Gynaecology, Mahatma Gandhi Mission Medical College and Hospital, Kalamboli, Navi, Mumbai.

3. Associate Professor, Department of Obstetrics and Gynaecology, Mahatma Gandhi Mission Medical College and Hospital, Kalamboli, Navi, Mumbai.
4. Head of Department, Department of Obstetrics and Gynaecology, Mahatma Gandhi Mission Medical College and Hospital, Kalamboli, Navi, Mumbai.

\section{NAME ADDRESS EMAIL ID OF THE CORRESPONDING AUTHOR:}

Dr. Mandavi Rai,

$2^{\text {nd }}$ Year Post Graduate Student,

MGM Hospital, PG Hostel,

Kamothe, Navi, Mumbai- 410209.

E-mail: mandavirai@yahoo.com

Date of Submission: 10/03/2014.

Date of Peer Review: 11/03/2014.

Date of Acceptance: 21/03/2014.

Date of Publishing: 07/04/2014. 